\title{
The study of past damaging hydrogeological events for damage susceptibility zonation
}

\author{
O. Petrucci and A. A. Pasqua \\ CNR-IRPI, Via Cavour 4/6, 87030 Rende, Cosenza, Italy
}

Received: 26 February 2008 - Revised: 14 May 2008 - Accepted: 7 July 2008 - Published: 19 August 2008

\begin{abstract}
Damaging Hydrogeological Events are defined as periods during which phenomena, such as landslides, floods and secondary floods, cause damage to people and the environment.
\end{abstract}

A Damaging Hydrogeological Event which heavily damaged Calabria (Southern Italy) between December 1972, and January 1973, has been used to test a procedure to be utilised in the zonation of a province according to damage susceptibility during DHEs. In particular, we analyzed the province of Catanzaro $\left(2391 \mathrm{~km}^{2}\right)$, an administrative district composed of 80 municipalities, with about 370000 inhabitants.

Damage, defined in relation to the reimbursement requests sent to the Department of Public Works, has been quantified using a procedure based on a Local Damage Index. The latter, representing classified losses, has been obtained by multiplying the value of the damaged element and the percentage of damage affecting it.

Rainfall has been described by the Maximum Return Period of cumulative rainfall, for both short $(1,3,5,7,10$ consecutive days) and long duration (30, 60, 90, 180 consecutive days), recorded during the event.

Damage index and population density, presumed to represent the location of vulnerable elements, have been referred to Thiessen polygons associated to rain gauges working at the time of the event.

The procedure allowed us to carry out a preliminary classification of the polygons composing the province according to their susceptibility to damage during DHEs. In high susceptibility polygons, severe damage occurs during rainfall characterised by low return periods; in medium susceptibility polygons maximum return period rainfall and induced damage show equal levels of exceptionality; in low susceptibility

Correspondence to: O. Petrucci

(o.petrucci@irpi.cnr.it) polygons, high return period rainfall induces a low level of damage.

The east and west sectors of the province show the highest susceptibility, while polygons of the N-NE sector show the lowest susceptibility levels, on account of both the low population density and high average rainfall characterizing these mountainous areas.

The future analysis of further DHEs, using the tested procedure, can strengthen the obtained zonation. Afterwards, the results can prove useful in establishing civil defence plans, emergency management, and prioritizing hazard mitigation measures.

\section{Introduction}

Natural hazards are geophysical events, such as earthquakes, landsliding, volcanic activity and flooding, which threaten the social entities of the Earth. Vulnerability associated to natural hazards may be defined as an internal risk factor, of the subject or system, which is exposed to a hazard and corresponds to its intrinsic predisposition to being affected by, or being susceptible to damage (Cardona, 2004).

Despite the fact that rainfall is an essential component of the environment, the space-time combination of rainfall intensity/duration and landscape and anthropogenic framework can induce Damaging Hydrogeological Events (DHEs).

A DHE can be defined as the whole of phenomena triggered by rainfall (Petrucci and Polemio, 2002, 2003), namely, floods, secondary floods (stagnancy of rain on low permeable surfaces) and landslides. While the term landslide is generally used to define all kinds of mass movements, regardless of the triggering causes, in the present work we only deal with landslides triggered by rainfall.

Published by Copernicus Publications on behalf of the European Geosciences Union. 
Rainfall capable of perturbing the equilibrium of environmental processes is specific to each area, according to both the geological framework, and climatic conditions which act upon the landscape over a prolonged period of time (Govi et al., 1985). Thus, for a study area, the relationship between rainfall and phenomena materialised during past events can be used to typify DHEs. By assuming the behaviour of processes to be uniform, the analysis of the recent past enables forecasting similar periods in the future (Remondo et al., 2008). In general, the results of rainfall thresholds methods have to be strengthened using more complex models. However, they can be applied as preliminary methods, especially where the absence of specifically gathered data does not allow the application of more sophisticated approaches.

There are many methodologies that allow for the separate analysis of phenomena which occur during DHEs. Pioneer studies concerning landslides triggered by rainfalls go back to the 30s (Záruba, 1936). Since then, several approaches have been proposed to assess the threshold, namely the minimum rainfall height (or intensity) required for landslide initiation (Campbell, 1975; Caine, 1980; Govi et al., 1985; Cancelli and Nova, 1985; Cascini and Versace, 1986; Cannon and Ellen, 1985; Jibson, 1989; Polemio and Sdao, 1996; Au, 1998; Polemio and Petrucci, 2000; Guzzetti et al., 2007). The results have been used also to develop warning systems and strategies for loss mitigation (Sirangelo and Braca, 2004; Aleotti, 2004; Fan-Chien et al., 2007).

Concerning floods, forecasting systems, which are aimed at minimizing damage caused by events which exceed a critical level, represent one of the most effective methods of non-structural flood management. These systems consist of a telemetry network that collects hydro-meteorological data in real time, and mathematical models to simulate response of catchments during flood occurrence. Significant advances have been done in prediction and management of both floods of large rivers (Chowdhury, 2000; Plate, 2007) and flash floods characterizing small basins (Hsu et al., 2003), also using GIS technologies (Usul and Turan, 2006).

Secondary floods arise when intense rainfall floods impervious, natural or non-natural surfaces. Water can simply flow into the basements of a few houses, or it can inundate large parts of cities for several days. The study approach may be based on a simulated one-dimensional hydrodynamic model, taking interactions between buried pipe system, streets and flooded areas into account (Mark et al., 2004). Total damage depends on the water level above ground level, as well as the extent and duration of flooding and flow velocity (Schmitt et al., 2004). In Italy, there are recent cases of casualties caused by these phenomena, namely in 1996 (Caloiero et al., 1996) and 2003, in Sicily, and in 2007, in Campania (the last two only quoted by newspapers).

Besides these approaches, which focus on a single type of phenomena, other works employ a global approach, analysing all the types of phenomena triggered during DHEs
(Barnikel and Becht, 2003; Diodato, 2004; Giannecchini, 2005; Luino, 2005).

The present paper proposes a global methodological approach for DHE characterisation, partially developed in previous works (Petrucci et al., 2003; Petrucci and Polemio, 2003). Using the study of the most severe documented DHE, a methodology for preliminary zonation of the study area, according to the susceptibility to the development of damaging phenomena during DHEs, has been attempted out. The main efforts have been carried out in the definition of the methodological steps. In any case, the results obtained by studying the most severe DHE that occurred in an area represent a starting point that can be strengthened by studying a complete series of DHEs. The final results which may be obtained can prove useful both in establishing civil defence plans and in the management of emergency phases.

\section{Methodology}

The proposed methodology is based on the comparative analysis of rainfall and damage that occurred in an area during the most severe DHE documented and aims to map this area according to damage susceptibility during prolonged and/or intense rainfall. This approach can be used when detailed damage and rainfall data are available. Long and complex historical research has to be conducted to obtain detailed data on large territorial sectors.

We have chosen to set the methodology using the most severe event documented in a study area for two reasons: a) the chosen event can be considered representative of the main severe events occurring in the study area; b) this event presents the worst damage scenario, so, in absence of more reliable data and methodologies, the results obtained using this event can supply at least preliminary indications.

Obviously, in order to obtain a damage susceptibility zonation having a solid statistical significance, a series of DHEs, characterised by different severity levels, has to be studied.

It is worth underlining that the proposed approach suggests a starting point, aiming to make a constructive contribution in the correlation of rainfall data on one hand and damage data on the other. The approach can be improved by applying the methodology to other study areas. Furthermore, in order to test the obtained results, a comparison of the zonation to the effect of events occurring nowadays can also be useful.

We have tried to achieve objectives stated above by means of the steps listed in the paragraphs below.

\subsection{Gathering of historical data}

For a study area, we selected the most severe DHE, for which indication of high damage induced were documented and available. 
There is a large number and variety of documents in which historical data may appear sporadically or systematically (Ibsen and Brunsden, 1996; Llasat et al., 2006). Furthermore, this information does not always directly describe a particular phenomenon, but rather may simply expose its effects or impact (proxy-data) (Benito et al., 2004).

Lastly, not all information is of optimum reliability and requires the critical analysis of its sources (Glaser, 1996).

In Italy, requests for damage compensation describe damage on a municipal scale, as a "final result of the event". Generally, the smallest amount of information concerns the funds designed to repair the damage in each municipality. Details on the types of phenomena that occurred and the names of the damaged places can also be found, but this is not a general rule.

Generally, historical data for damage compensation are affected by the following restrictions:

1. research can never be considered complete, because accidental factors can cause document loss;

2. damage is considered in reference to municipalities, so administrative boundaries have to be taken into account;

3. phenomena which occurred in unmanned areas and did not induce damage are excluded, so, the figure of phenomena (but not of damage) can be underestimated;

4. applications were often performed using prescribed forms, in which events are indicated by the year of occurrence (i.e. Event of 1951). Thus, the requests depict the final result of the event, and not the exact days during which damage occurred.

Taking account of these limitations, for each municipality, database records containing the description of the type/types of triggered phenomena, and the damaged elements can be created.

According to the procedure described in previous works, for each municipality we assessed the Local Damage Index (LDI). If observed damage is the product of the value of the element at risk and its level of loss, for the $i_{t h}$ damage, a Damage Index can be calculated by multiplying the value of the element at risk (ranging between 1 and 10, in an arbitrary scale) (Petrucci et al., 2003), by the Level of Damage, that is a measure of the percentage of loss affecting the element during the event (High=1 for Level 1; Medium=0.5 for Level 2; Low $=0.25$ for Level 3 ).

LDI is the sum of all loss caused within a municipality by the $I$ cases of damage that occurred there. So, we assessed LDI for all the municipalities of the study area and ranked the obtained values in 4 classes (Table 1) in order to predispose the data for the comparative analysis with rainfall.
Table 1. Classification of Local Damage Index (LDI).

\begin{tabular}{lc}
\hline Class & LDI \\
\hline 1 & $<10$ \\
2 & $10 \leq$ LDI $<20$ \\
3 & $20 \leq$ LDI $<30$ \\
4 & $>30$ \\
\hline
\end{tabular}

\subsection{Gathering of rainfall data}

The historical series of rainfall had to be prepared for the rain gauges working at the time of the event.

We used a GIS software to trace Thiessen polygons (hereinafter influence polygon), coupled with the rain gauges working at the time of the event (ESRI, 1998). More sophisticated methods could be used to define areas of influence around gauges, but, in light of the fact that damage data are related to a municipal scale, the accuracy of this approach seemed suitable.

Because damage data show the character of a "final balance", we arbitrarily assumed the whole of damage to be the effect of the most severe rainfall that occurred during the event.

In order to take the effect of cumulative rainfall into account, we selected a period which entirely covered the time in which the event took place. In practice, we set a time frame extending to the time before and after the maximum daily rainfall of the event. For DHEs developing in less than a week, a time frame of 60 days seemed adequate.

To characterise rainfall, we assessed the cumulative rainfall for different duration periods $(1,3,5,7,10,30,60,90$, 180 consecutive days) for each day within the established time frame. Then, we assessed Return Periods (RP) of the aforementioned cumulative rainfall, using the historical series of rainfall as our basis.

Cumulative Rainfalls $\left(\mathrm{CR}_{n j}\right)$ were calculated using the hydrological year (from 1 September to 31 August) as a base period. In $\mathrm{CR}_{n j}, n$ corresponds to $1,3,5,7,10,30,60,90$, 180 consecutive days, and $j$, ranging from 1 to 364 , is the number of days of the observation period.

In order to assess return periods of each $\mathrm{CR}_{n j}$, we used the Gumbel distribution. The Gumbel parameters have been defined by the Moments Method, that is by changing $n$ and the gauge, the parameters for each series of cumulative rainfall can be defined (Versace et al., 1989). Therefore, using the Gumbel function, the Return Period for each $\mathrm{CR}_{n j}$ variable can been assessed.

For each rain gauge and each day of the analyzed duration periods $(1,3,5,7,10,30,60,90$, and 180), we assumed the Maximum Rainfall Return Period (MRRP) obtained during a two months time frame to be indicative of the event. 
Table 2. Classification of Maximum Rainfall Return Periods (MRRP).

\begin{tabular}{lc}
\hline Class & MRRP (Years) \\
\hline 1 & MRRP $<5$ \\
2 & $5 \leq \mathrm{MRRP}<50$ \\
3 & $50 \leq \mathrm{MRRP}<100$ \\
4 & $\mathrm{MRRP} \geq 100$ \\
\hline
\end{tabular}

This approximation helps by-pass the problem that we quoted in Sect. 2.1, that is the fact that historical documents depict the final result of the event, and not the exact days during which damage occurred (pre-printed forms for damage compensation are labelled: "Event of December 1972/January 1973 ").

The event hit a large area and we have no data regarding the exact days during which damage affected the area's different sectors. However, during a DHE, it is presumable that the effects of rainfall manifest according to the movement of weather fronts causing the rainfall, which occurs in more than in a few days. For these reasons it is necessary to set a criterion capable of systematically taking into account the whole rainfall period during which different sectors are hit. We undoubtedly introduce a simplification assuming that MRRP obtained during a two month time frame is indicative of the event. In any case the systematic analysis of rainfall in the above mentioned time frame ensures that all rainfall contribution is taken into account. This may not seem particularly relevant for damaging phenomena which show an immediate response to intense rainfall (flash floods, secondary floods or shallow landslides), but, in the case of deep seated landslides (mostly tied to prolonged rainfall), leaving aside this aspect can cause an underestimation of rainfall responsible for the triggering.

Maximum Rainfall Return Periods (MRRP) were ranked according to Table 2 . In order to characterise rainfall, both globally and in long and short terms respectively, for each gauge, we calculated the Average of MRRP (classified according to Table 2) for the following number of consecutive days: 1) from 1 to $180\left(\mathrm{~A}-\mathrm{MRRP}_{1-180 \mathrm{~d}}\right.$ ); 2) from 1 to 10 $\left.\left(\mathrm{A}-\mathrm{MRRP}_{1-10 \mathrm{~d}}\right) ; 3\right)$ from 30 to 180 (A-MRRP $\left.30-180 \mathrm{~d}\right)$.

\subsection{Arrangement of historical data of damage}

Historical documents describe damage which occurred in each municipality. Therefore, to compare rainfall to damage, we carried out some geometrical elaborations to refer LDI to influence polygons.

The GIS layer of influence polygons was intersected with the layer of municipalities of the study area. As a result, each influence polygon $n$ was subdivided in $\alpha$ parts that we called Municipal Sectors (MS). For the generic MS $j$, we know the area $\left(A_{\mathrm{MS} j}\right)\left(\mathrm{km}^{2}\right)$, the municipality to which it belongs $(l)$, and, thus, the value of $\mathrm{LDI}\left(\mathrm{LDI}_{l}\right)$. Using the Eq. (1), we ex-
Table 3. Classification of Population Density (PD) (inh/ $\left.\mathrm{km}^{2}\right)$.

\begin{tabular}{lc}
\hline Class & $\mathrm{PD}\left(\mathrm{inh} / \mathrm{km}^{2}\right)$ \\
\hline 1 & $\mathrm{PD}<50$ \\
2 & $50 \leq \mathrm{PD}<100$ \\
3 & $100 \leq \mathrm{PD}<200$ \\
4 & $\mathrm{PD} \geq 200$ \\
\hline
\end{tabular}

pressed the area of $\mathrm{MS}_{j}$ as a percentage of the area of polygon $n\left(A_{n}\right)\left(\mathrm{km}^{2}\right)$ in which it is included:

Percentage $\mathrm{MS}_{j}=\frac{A_{\mathrm{MS} j}}{A_{n}} \times 100$

The product of Percentage $\mathrm{MS}_{j}$ and $\mathrm{LDI}_{l}$, classified according to the values of Table 1 , give $\mathrm{LDI}_{\mathrm{MS} j}$, which is the contribution provided by the municipality sector $j$ to the LDI of the polygon $n(2)$.

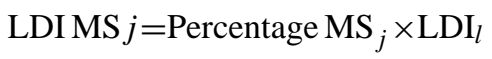

After this calculation has been carried out for the $\alpha$ municipal sectors included in the polygon $n$, the LDI of polygon $n$ can be obtained using the Eq. (3):

$\mathrm{LDI}_{n}=\sum_{1}^{M} \frac{\mathrm{LDI}_{\mathrm{MS} j}}{100}$

For all available influence polygons we classified $\mathrm{LDI}_{n}$ according to Table 1, in order to compare values to rainfall recorded in the rain gauge of the analysed polygon.

\subsection{Arrangement of density population data}

We can assume Population Density (PD) at the time of the event as roughly indicative of the distribution of vulnerable elements.

The number of residents in each municipality can be obtained from the results of the national census closest to the event. Hence, the number of inhabitants of the municipal sector $j\left(\mathrm{Nin}_{\mathrm{MS}} j\right)$ can be assessed using the Eq. (4), in which $\mathrm{Nin}_{l}$ is the number of inhabitants resident in the municipality $l$ (to which the sector belongs), $A_{\mathrm{MS} j}\left(\mathrm{~km}^{2}\right)$ is the area of municipal sector $j$, and $A_{l}\left(\mathrm{~km}^{2}\right)$ is the area of municipality $l$.

$\operatorname{Nin}_{\mathrm{MS} j}=\frac{\operatorname{Nin}_{l} \times A_{\mathrm{MS} j}}{A_{l}}$

The sum of $\operatorname{Nin}_{\mathrm{MS} j}$, for the $\alpha$ municipal sectors included in the polygon $n$, divided by the area of the polygon $n$ $\left(A_{n}\right)$ express the population density of the polygon $n\left(\mathrm{PD}_{n}\right)$ (Eq. 5).

$P D_{n}=\sum_{1}^{M} \frac{\mathrm{Nin}_{\mathrm{MS} j}}{A_{n}}$

We classified values of PD (inh/ $\mathrm{km}^{2}$ ) according to Table 3 . 


\subsection{Arrangement of data concerning damaging phenomena}

Finally, the types of phenomena were also qualitatively related to the influence polygons.

Historical data of damage compensation do not supply the exact number of phenomena that occurred and the exact delimitation of hit areas. For example, a hypothetical historical document describing widespread shallow landslides can quote the type of phenomena (landslide), their diffusion (...a lot of landslides), indication of the size (...a lot of small landslides), and damaged elements (...a lot of small landslides damaged the State Road from 100 to $101 \mathrm{~km}$ ). In practice, we are provided with indication of the presence of a type of phenomena but we do not find a list of phenomena that occurred. Thus, the data allowed us to infer the occurrence/nonoccurrence of a certain type of phenomenon rather than the mapping of the phenomenon itself. Concerning this aspect, and considering the temporary effects of some kinds of phenomenon, only detailed surveys, carried out immediately after the event, could supply data. What is more, we analysed documents describing "damaging" phenomena, hence, if a list is available, it excludes non-damaging phenomena.

Taking into account the fact that we deal with noninstrumental data, and that they are the only kind of data available for the reconstruction of damage scenario, the aim was that of acquiring an "information base" obtainable from each document. The occurrence/non occurrence of a certain type of phenomenon can be considered basic information, also representing a sort of "susceptibility" to the type of phenomenon.

Furthermore, phenomena were referred to influence polygons. For MS $j$ we know: the area $\left(A_{\mathrm{MS} j}\right)$ and the type/s of phenomena which affected it during the event (Landslide, Flood, Secondary flood). We defined a Factor for each type of phenomena: $F_{L}$ (Landslide), $F_{F}$ (Flood) and $F_{S}$ (Secondary flood), having a relative "weight" according to the area of the municipality sector in which they occurred. For example, Factor landslide for the polygon $n\left(F_{L n}\right)$ can be obtained by the Eq. (6), substantially equal to the Eq. (1):

$F_{L n}=\sum_{1}^{M} \frac{A_{\mathrm{MS} j} \times 100}{A_{n}}$

The obtained values were classified according to Table 4 .

\subsection{Comparative analysis of rainfall and damage}

At this point, for each polygon we assessed and classified: a) damage, expressed by $\mathrm{LDI}_{n} ;$ b) rainfall, expressed by MRRP recorded during the event; c) presence of vulnerable elements, synthesized by population density $\left(\mathrm{PD}_{n}\right)$; d) types of triggered phenomena, synthesized by three Factors $\left(F_{L n}, F_{F n}\right.$ and $\left.F_{S n}\right)$.

Theoretically, if we assume that vulnerable elements are homogeneously distributed throughout the study area, we can foresee some kind of relation between rainfall and level of
Table 4. Classification of Factors expressing the relative incidence of landslides $\left(F_{L}\right)$ floods $\left(F_{F}\right)$ and secondary floods $\left(F_{S}\right)$ in each influence polygon.

\begin{tabular}{lc}
\hline Class & $F\left(F_{L}-F_{F}-F_{S}\right)(\%)$ \\
\hline 1 & $F<25$ \\
2 & $25 \leq F<50$ \\
3 & $50 \leq F<75$ \\
4 & $F \geq 75$ \\
\hline
\end{tabular}

damage. In reality, a comparison between A-MRRP and LDI can lead to three possible cases:

1) Low classes of A-MRRP are coupled to high classes of $L D I$. This happens in polygons characterised by high susceptibility to DHEs, which, during the events, undergo the highest levels of damage or, in any case, of a level higher than what could be expected considering MRRP.

2) A-MRRP and LDI are placed in similar classes. This happens in polygons where, after high/low MRRP, high/low damage occurs. These polygons show medium susceptibility to damage caused by DHEs.

3) High classes of A-MRRP are coupled to low classes of LDI. Damage after DHEs is lower than what could be expected according to MRRP. These polygons, where the environment seems to cope with heavy rainfall, can be characterised as having a low susceptibility to DHEs.

We must to stress the fact that we related the concept of susceptibility to the three types of phenomena as a whole. In any case, for each polygon, the tendency to develop one type of phenomenon more than another is expressed by $F_{L}, F_{F}$ and $F_{S}$.

\section{A case study: the DHE of December 1972-Januar 1973 in Catanzaro province}

In Calabria, DHEs often cause victims, homelessness, and damage to roads, lifelines and villages (Caloiero and Mercuri, 1980; Catenacci, 1992; Petrucci et al., 1996; D’Andrea and Petrucci, 2003; Sorriso et al., 2004; Petrucci and Versace, 2005, 2007).

Recently, a database named ASICal (Aree Storicamente Inondate in CALabria) has been implemented (Petrucci and Versace, 2004). At the present, ASICal, which contains about 6000 data on Calabria's historical landslides, floods, secondary floods and sea storms, is available on the following website: http://www.camilab.unical.it.

In order to access and use of rainfall data (being gathered in Calabria since 1921), we selected a DHE which occurred between December 1972, and January 1973, among all DHEs dating no further back than 1921. 


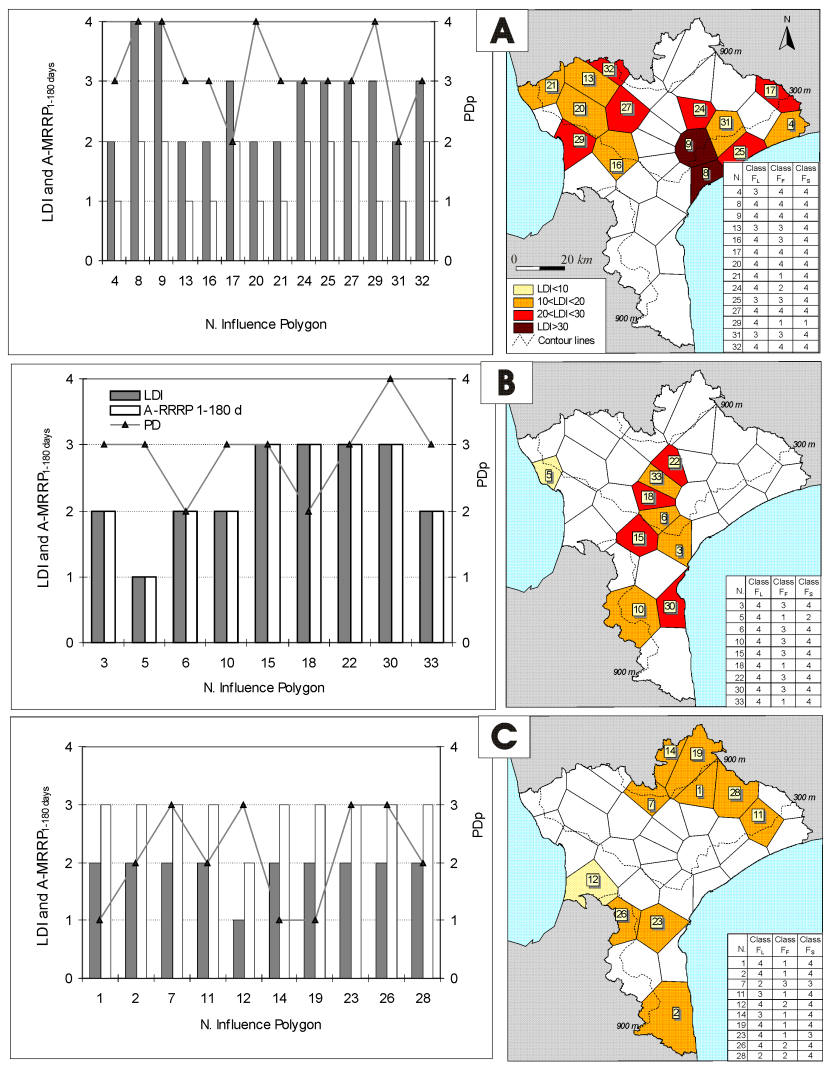

Fig. 1. Comparative analysis of LDI (Local Damage Index) and A-MRRP $1-180 \mathrm{~d}$ (Average of Maximum Rainfall Return Period) of cumulative rainfall with a duration of 1 to 180 consecutive days. $\mathrm{PD}=$ Population Density of polygon; $N=$ Number of polygon; Class $F_{L}=$ class of Factor landslide; $F_{F}=$ class of Factor flood; $F_{S}=$ class of Factor secondary flood.

A deep historical research in an unorganised archive of the regional Department of Public Works allowed us to obtain detailed information concerning damage, for each municipality in the province of Catanzaro.

Economic losses all over the region were estimated in \$150 Million US (Giangrossi, 1973). In 17 of Calabria's rain gauges, the maximum daily rainfall recorded during the event represented the maximum value recorded between 1921 and 2008: 10 of these gauges were located in the province of Catanzaro.

\subsection{The study area}

Calabria, the southern-most Italian region, is a peninsula which has a surface of $15230 \mathrm{~km}^{2}$, a perimeter of $738 \mathrm{~km}$, and a mean and maximum altitude of 418 and $2266 \mathrm{~m}$ a.s.l., respectively. Almost $90 \%$ of regional territory is in relief and $10 \%$ is represented by coastal and fluvial plains.

From an administrative point of view, the region is divided into five provinces.
The climate can be classified as Mediterranean, with drysummers (monthly minimum rainfall in July or August) and wet-winters (monthly maximum rainfall in December or January). The mean annual rainfall $(1151 \mathrm{~mm})$ is higher than the national value $(970 \mathrm{~mm})$.

The region is made up of a stack of allochthonous terrains (from Palaeozoic to Jurassic), made of crystalline rocks, mainly gneiss and granite, derived from both continental and oceanic crust, stacked, during middle Miocene (Tortorici, 1982), over the carbonate units of northern Calabria (Ogniben, 1973). During the emplacement of terrains and onwards, Neogene's tectonic melange and flysch built a substratum that underwent extension because of uplift which started in Quaternary and it is still active.

The present work focuses on the province of Catanzaro, in central Calabria. This administrative district $\left(2391 \mathrm{~km}^{2}\right)$, has a mean altitude of $320 \mathrm{~m}$ a.s.l., is comprised of 80 municipalities and has a population of about 370000 residents.

From a morphological point of view, the analysed province is made up of a large graben, oriented WNW-WSE, bordered, to the North and South, by two horsts. The graben, called Stretta di Catanzaro, is filled with plio-quaternary sediments, and emerged during Quaternary. The two horsts are made of granites and metamorphic rocks belonging to the Calabro Peloritan Arc (Amodio-Morelli et al., 1976).

The Stretta di Catanzaro is a highly dynamic area. A recent survey detected 119 mass movements, mainly located in sedimentary terrains, the great part which are quiescent (Antronico et al., 2001; Gullà et al., 2005). The fact that this sector of the study area is highly prone to rainfall-triggered phenomena is also demonstrated by the high number of landslides and floods detected through historical research focusing on the period between 1638 and 1990 (Rizzo and Fragale, 1999).

\subsection{Gathering and setting of data}

We analysed about 4000 documents concerning the period December 1972-January 1973, obtained from the archive of the Calabrian Department of Public Works. Data concerning landslides, floods and secondary floods, which occurred throughout the province of Catanzaro during the event that took place in the above mentioned period, were obtained. In the study area, the elements most severely damaged by the analysed event were private houses (8122 cases of damage), public buildings (142 cases), road network (99 cases) and services network (65 cases).

For each municipality, we assessed LDI and classified values according to Table 1.

Concerning rainfall, the most severe daily rainfall was concentrated in two periods, the first one dating from 22 to 24 December 1972, and the second one from 31 December 1972 to 3 January 1973. 
Table 5. Maximum Rainfall Return Periods (MRRP), assessed in each gauge, for $1,3,5,7,10,30,60,90,180$ consecutive days, during the period 1 December 1972-30 January 1973, classified according to Table 2 .

\begin{tabular}{|c|c|c|c|c|c|c|c|c|c|c|c|}
\hline N. & Gauge & $\begin{array}{c}\text { Altitude } \\
\text { m a.s.l. }\end{array}$ & $\begin{array}{l}1 \\
d\end{array}$ & $\begin{array}{l}3 \\
\mathrm{~d}\end{array}$ & $\begin{array}{l}5 \\
d\end{array}$ & $\begin{array}{l}7 \\
\mathrm{~d}\end{array}$ & $\begin{array}{r}10 \\
\mathrm{~d}\end{array}$ & $\begin{array}{r}30 \\
\mathrm{~d}\end{array}$ & $\begin{array}{r}60 \\
d\end{array}$ & $\begin{array}{r}90 \\
\mathrm{~d}\end{array}$ & $\begin{array}{r}180 \\
\mathrm{~d}\end{array}$ \\
\hline 1 & Albi & 717 & 4 & 4 & 4 & 4 & 4 & 3 & 2 & 2 & 1 \\
\hline 2 & Badolato & 250 & 2 & 2 & 3 & 3 & 4 & 3 & 3 & 2 & 2 \\
\hline 3 & Borgia & 332 & 2 & 2 & 2 & 2 & 2 & 2 & 2 & 2 & 1 \\
\hline 4 & Botricello & 18 & 1 & 1 & 2 & 1 & 2 & 1 & 1 & 1 & 1 \\
\hline 5 & Capo Suvero & 20 & 1 & 1 & 1 & 1 & 1 & 1 & 1 & 1 & 1 \\
\hline 6 & Caraffa & 370 & 3 & 3 & 2 & 2 & 3 & 2 & 2 & 2 & 1 \\
\hline 7 & Carlopoli & 950 & 3 & 4 & 4 & 4 & 4 & 2 & 2 & 1 & 1 \\
\hline 8 & Catanzaro L. & 6 & 1 & 2 & 2 & 2 & 2 & 2 & 2 & 2 & 2 \\
\hline 9 & Catanzaro & 347 & 3 & 3 & 2 & 2 & 3 & 2 & 3 & 2 & 2 \\
\hline 10 & Chiaravalle & 550 & 1 & 1 & 2 & 2 & 2 & 2 & 2 & 2 & 1 \\
\hline 11 & Cropani & 348 & 2 & 2 & 3 & 4 & 4 & 3 & 3 & 2 & 2 \\
\hline 12 & Curinga & 380 & 2 & 2 & 3 & 2 & 3 & 2 & 2 & 1 & 1 \\
\hline 13 & Decollatura & 780 & 1 & 2 & 1 & 1 & 1 & 1 & 1 & 1 & 1 \\
\hline 14 & Fiorenza & 1126 & 3 & 4 & 4 & 4 & 4 & 2 & 2 & 2 & 1 \\
\hline 15 & Girifalco & 450 & 4 & 4 & 4 & 3 & 4 & 4 & 3 & 2 & 2 \\
\hline 16 & Maida & 300 & 1 & 1 & 1 & 1 & 1 & 1 & 1 & 1 & 1 \\
\hline 17 & Marcedusa & 314 & 2 & 2 & 2 & 2 & 3 & 3 & 3 & 2 & 2 \\
\hline 18 & Marcellinara & 330 & 4 & 4 & 4 & 3 & 3 & 3 & 2 & 2 & 2 \\
\hline 19 & Monaco & 1250 & 3 & 4 & 4 & 4 & 3 & 2 & 2 & 2 & 1 \\
\hline 20 & Nicastro & 200 & 1 & 2 & 2 & 1 & 1 & 1 & 1 & 1 & 1 \\
\hline 21 & Nocera $\mathrm{T}$. & 250 & 1 & 2 & 1 & 1 & 1 & 1 & 1 & 1 & 1 \\
\hline 22 & Olivella & 360 & 4 & 4 & 4 & 4 & 4 & 4 & 3 & 2 & 2 \\
\hline 23 & Palermiti & 480 & 3 & 3 & 3 & 2 & 3 & 4 & 3 & 2 & 2 \\
\hline 24 & S. Elia & 650 & 3 & 3 & 3 & 2 & 2 & 2 & 2 & 2 & 1 \\
\hline 25 & Sellia Marina & 30 & 1 & 2 & 2 & 2 & 2 & 2 & 2 & 2 & 2 \\
\hline 26 & Serra del Gelo & 800 & 3 & 4 & 4 & 4 & 4 & 4 & 4 & 2 & 2 \\
\hline 27 & Serrastretta & 790 & 2 & 2 & 2 & 2 & 2 & 1 & 1 & 1 & 1 \\
\hline 28 & Sersale & 750 & 3 & 3 & 3 & 2 & 3 & 3 & 4 & 3 & 2 \\
\hline 29 & S. Eufemia & 25 & 1 & 1 & 1 & 1 & 1 & 1 & 1 & 1 & 1 \\
\hline 30 & Soverato & 6 & 2 & 3 & 4 & 3 & 3 & 2 & 2 & 2 & 2 \\
\hline 31 & Soveria Simeri & 366 & 1 & 1 & 2 & 1 & 1 & 2 & 2 & 1 & 1 \\
\hline 32 & S. Tommaso & 820 & 2 & 3 & 2 & 2 & 2 & 1 & 1 & 1 & 1 \\
\hline 33 & Tiriolo & 690 & 4 & 3 & 2 & 2 & 2 & 2 & 2 & 2 & 1 \\
\hline
\end{tabular}

At the time of the event, in the study area, 33 rainfall gauges were working. For these gauges, daily data concerning the period from 1921 to 2006 were available (http: //www.protezionecivilecalabria.it/). During this period, the largest number of years of observation concerns gauges N. 9 and 10 (93 y). Considering all the available gauges, the mean value of years of observation is 68.21.

For 10 gauges (30\% of the total), the maximum daily rainfall of December 1972 is the maximum value of the entire observation period (1921-2006). Furthermore, in every one of the 33 gauges, the maximum daily rainfall recorded during the event is equal to or greater than $10 \%$ of the average annual rainfall. The highest values of daily rainfall were recorded in gauges $1(481.9 \mathrm{~mm}), 15(400.3 \mathrm{~mm}), 18$ $(301.1 \mathrm{~mm})$ and $22(524.2 \mathrm{~mm})$.

We established the time frame to be analyzed from 1 December 1972 to 31 January 1973. Then, basing on the historical series of rainfall (1921-2006), we assessed Maximum Rainfall Return Periods (MRRP) for 1, 3, 5, 7, 10, 30, 60, 90, 180 consecutive days, and we ranked them according to Table 2, as shown in Table 5. Thiessen polygons, coupled to the 33 rain gauges available at the time of the event, were traced

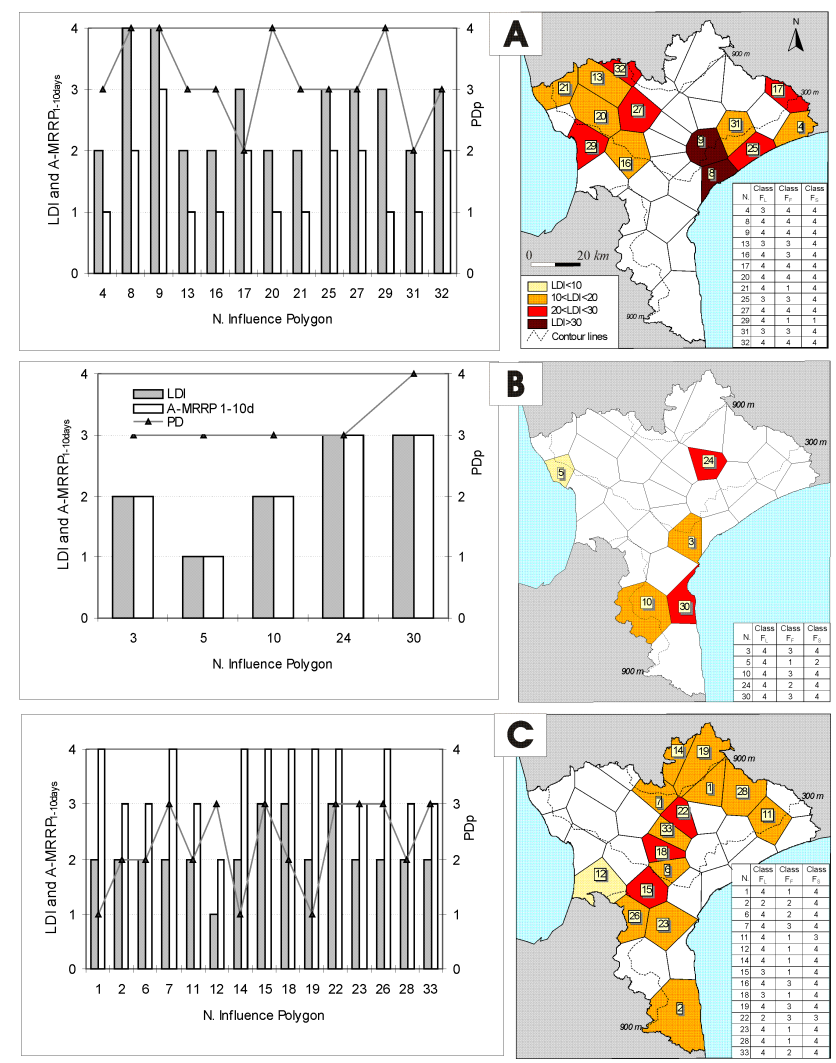

Fig. 2. Comparative analysis of LDI (Local Damage Index) and A-MRRP $_{1-10 d}$ (Average of Maximum Rainfall Return Period) of cumulative rainfall with a duration of 1 to 10 consecutive days. $\mathrm{PD}=$ Population Density of polygon; $N=$ Number of polygon; Class $F_{L}=$ class of Factor landslide; $F_{F}=$ class of Factor flood; $F_{S}=$ class of Factor secondary flood.

using a GIS software (ESRI ArcView 3.2). According to the procedure described in Sect. 2.3, we assessed LDI of all the influence polygons in which the province of Catanzaro has been divided.

The results of the national census conducted closest to the event (ISTAT, 1971) constituted a starting point, after which we assessed population density for each influence polygon (see Sect. 2.4) and classified the values according to Table 3.

Finally, $F_{L}, F_{F}$ and $F_{S}$, for each polygon were assessed and classified according to Table 4 .

\subsection{Comparative analysis of damage and average of MRRP $_{1-180 \mathrm{~d}}$}

Keeping in mind that we are working on a single event in order to formulate a methodological approach, we present the results as a preliminary zonation of the study area that can be strengthened by applying the same methodology to others DHEs.

In Fig. 1, for each polygon, the averages of classified MRRP $_{1-180 \mathrm{~d}}$, have been compared to classified LDI. 


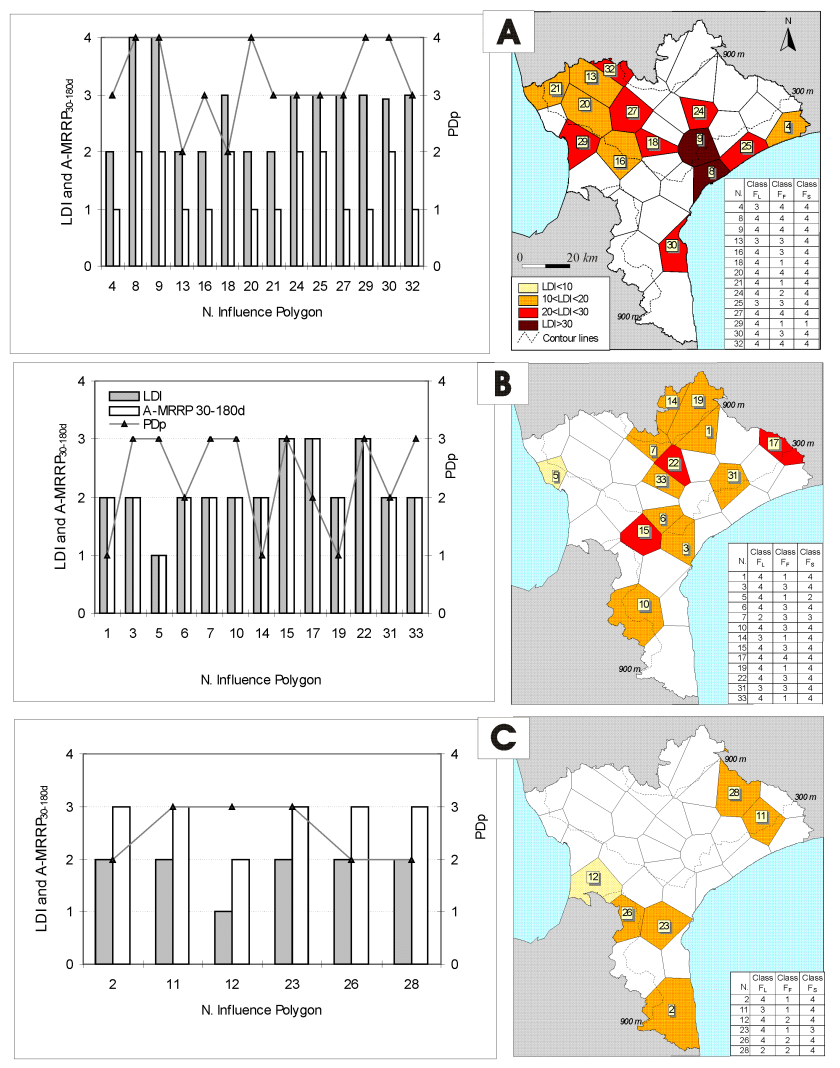

Fig. 3. Comparative analysis of LDI (Local Damage Index) and AMRRP $_{30-180 d}$ (Average of Maximum Rainfall Return Period) of cumulative rainfall with a duration of 30 to 180 consecutive days. $\mathrm{PD}=$ Population Density of polygon; $N=$ Number of polygon; Class $F_{L}=$ class of Factor landslide; $F_{F}=$ class of Factor flood; $F_{S}=$ class of Factor secondary flood.

In Fig. 1A, 14 polygons (42\%) in which low $\mathrm{MRRP}_{1-180 \mathrm{~d}}$ match high LDI, are coloured according to their LDI.

Except two cases (17 and 31), these polygons are characterised by a high population density. This explains the high levels of damage induced during the studied event. Polygons 8, 9 and 29 show the strongest difference among AMRRP $_{1-180 \mathrm{~d}}$ and LDI: all of them are characterised by the maximum class of population density. During the event, six polygons $(8,9,17,20,27$, and 32$)$ show similar proneness to the three types of phenomena (see table in Fig. 1A).

Polygons in which LDI and A-MRRP ${ }_{1-180 \mathrm{~d}}$ levels are roughly similar $(27 \%)$ show the highest tendency to develop landslides and secondary floods, with the exception of one case (5) (Fig. 1B).

In $30 \%$ of polygons, LDI is lower than what could have been expected (Fig. 1C): three of these polygons (1, 14 and 19) show a low PD class $\left(<50 \mathrm{inh} / \mathrm{km}^{2}\right)$. The low PD accounts for the low LDI: in scarcely populated areas, phenomena can occur without inducing damage, and this decreases LDI levels. Polygons with PD in class 3 (7, 12, 23 and 26), with the exception of one case (12), are related to gauges of

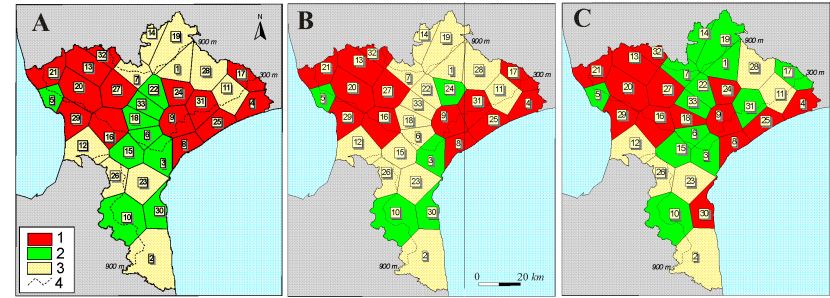

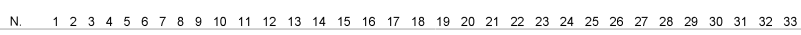
PD $1 \begin{array}{lllllllllllllllllllllllllllllllll}1 & 2 & 3 & 3 & 3 & 2 & 3 & 4 & 4 & 3 & 2 & 3 & 2 & 1 & 3 & 3 & 2 & 2 & 1 & 4 & 3 & 3 & 3 & 3 & 3 & 3 & 3 & 2 & 4 & 4 & 2 & 3 & 3\end{array}$

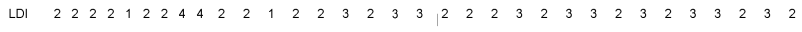

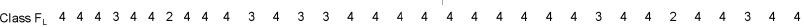
$\begin{array}{lllllllllllllllllllllllllllllllllll}\text { Class }_{F} & 1 & 1 & 3 & 4 & 1 & 3 & 3 & 4 & 4 & 3 & 1 & 2 & 3 & 1 & 3 & 3 & 4 & 1 & 1 & 4 & 1 & 3 & 1 & 2 & 3 & 2 & 4 & 2 & 1 & 3 & 3 & 4 & 1\end{array}$

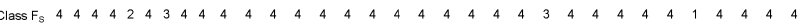

Fig. 4. Susceptibility zonation of the province of Catanzaro for damage induced by DHEs. Results obtained analysing different rainfall duration; in $\mathbf{A}$, from 1 to 180 days, in $\mathbf{B}$, from 1 to 10 days, in $\mathbf{C}$, from 30 to 180 days. 1) high susceptibility; 2) medium susceptibility; 3) low susceptibility; 4) contour lines. In the table: $N=$ Number of polygon; PD=Population Density; LDI=Local Damage Index of polygon; Class $F_{L}=$ class of Factor landslide; Class $F_{F}=$ class of Factor flood; Class $F_{S}=$ class of Factor secondary flood.

mountainous areas. This can cause two consequences: a) the high rainfall recorded at the gauge is not representative of the rainfall fallen on the polygon; b) in mountainous areas, which experience high values of average rainfall, the rainfall which can trigger DHEs is higher than in areas characterised by lower values of average rainfall. These polygons tend to be mainly affected by landslides and secondary floods.

\subsection{Comparative analysis of damage and average of MRRP $_{1-10 \mathrm{~d}}$}

For each polygon, by comparing the average values of

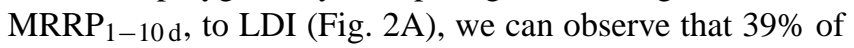
the polygons show high classes of LDI coupled to low classes of A-MRRP $1-10 \mathrm{~d}$. By considering the results obtained by studying the 1972/73 event as significant, these polygons can be considered susceptible to the development of damaging phenomena after rainfall of a short duration (until 10 days). In this group we find the densely populated polygons $(8,9$, 20 and 29, all characterised by class 4 of PD), mainly affected by secondary floods, a frequent type of phenomenon in impervious urbanised areas where asphalt or cement block or delay the natural process of rainfall infiltration.

Only for $15 \%$ of polygons A-MRRP $1-10 \mathrm{~d}$ and LDI show similar classes (Fig. 2B).

During the event, $45 \%$ of polygons show a low susceptibility to develop damaging phenomena after rainfall of 1 to 10 days, as may be noted in light of the fact that high classes of A-MRRP $1-10 \mathrm{~d}$ correspond to low values of LDI. In these cases, excluding polygons 7 and 23 , the most common type of phenomenon is secondary flooding. 
3.5 Comparative analysis of damage and average $\mathrm{MRRP}_{30-180 \mathrm{~d}}$

Reiterating the procedure for A-MRRP $30-180 \mathrm{~d}, 39 \%$ of polygons confirm their high susceptibility also after prolonged rainfall periods, experiencing high levels of damage after rainfall which is not particularly exceptional (Fig. 3A). These include the most populated polygons where mainly secondary floods develop.

Polygons characterised by equal levels of LDI and MRRP $_{30-180 \mathrm{~d}}$ increase to $39 \%$ of the total (Fig. 3B). 77\% of these polygons show the highest landslide factor and $84 \%$ the highest secondary flood factor.

The percentage of polygons classified as low susceptibility to DHEs decreases to 22\% (Fig. 3C).

\subsection{Discussion}

Before discussing the results we stress that the zonation of the study area has to be considered a preliminary step and needs to be confirmed by analysing others DHEs.

In Fig. 4, influence polygons have been coloured according to their susceptibility values obtained considering rainfall from 1 to 180 days (Fig. 4A), 1 to 10 (Fig. 4B) and 30 to 180 (Fig. 4C).

Analysing the entire event (Fig. 4A), 14 high vulnerability polygons are located in part on the western as well as on the eastern side of the province. They mainly lay between 300 and $900 \mathrm{~m}$ a.s.l. Population density ranges from class 2 , for the innermost polygons, to 4 , in some coastal polygons $(8,9)$. In 6 cases (42\%), the polygons show maximum susceptibility to landslides, floods and secondary floods simultaneously (8, $9,17,20,27$, and 32) and in the remaining cases the highest proneness is to landslides and/or secondary floods.

The great part of these polygons confirms high susceptibility when the short or long duration of rainfall are individually considered (Fig. 4B and 4C).

A zone of low susceptibility is located in the northern sector of the province: some of these polygons show low susceptibility both considering the entire event and short/long duration (11 and 28), the others (7, 14, 19 and 21) increase susceptibility to medium values for long term rainfall (Fig. 4). Low susceptibility zones (2, 12 and 26), both considering the entire event and short/long cumulative rainfall, are also located on the southern area of province.

Concerning low and medium susceptibility polygons, we can observe some modifications when short (Fig. 4B) and long duration (Fig. 4B) are considered. The great majority of polygons classified, according to short rainfall, as low susceptibility (1, 6, 7, 14, 15, 19, 22 and 33), increases to medium susceptibility when long duration is considered. Two cases ( 3 and 10) continue to be classified as medium susceptibility polygons both considering short and long duration, and only in one case (17) susceptibility decreases from high, for short duration, to medium, for long duration of rainfall.

In summary, the east and west sectors of the province show the highest susceptibility, both after long and short intense rainfall. Polygons in the N-NE sector show the lowest susceptibility levels. This depends on both low population density, and high average values of rainfall which these mountainous areas usually experience and render the landscape accustomed to experiencing intense rainfall.

Population density using the results of the most recent national census (ISTAT, 2001) has been assessed in order to provide up-to data results for our work. During the period 1971-2001, in several coastal municipalities, the number of residents increased, while, in mountainous municipalities this figure decreased. Nevertheless, population density of polygons substantially hold steady, except for polygon 7 , where we find a decrease from class 3 to 2 , and polygon 12 , where we find increase from class 3 to 4 . Consequently, analysis carried out and subsequent results based on the population density of 1971 still hold true today.

\section{Conclusions}

A severe DHE which occurred in the province of Catanzaro in the winter of 1972/73 has been used to formulate and test a procedure for carrying out a zonation of the province according to the susceptibility to damage during DHEs. We would like to point out that, in the present work we have analysed a single DHE and, for this reason, the result is a preliminary zonation of the study area that has to be supported by applying the same methodology to other DHEs.

Damage, defined in relation to the reimbursement requests sent to the Department of Public Works, has been quantified using a procedure based on a Local Damage Index. The latter has been obtained by multiplying the value of the damaged element and the percentage of damage affecting it. LDI values have been divided in 4 classes of increasing degree of severity (Table 1).

Rainfall has been described by the Maximum Return Period of cumulative rainfall recorded during a two month time frame which encompasses the event. These values have been classified and synthesized by their average values, for both short (1, 3, 5, 7, and 10) and long duration (30, 60, 90, 180 consecutive days).

Rainfall, damage index, and population density, assumed to represent the location of vulnerable elements, have all been referred to Thiessen polygons and associated to rain gauges working during the event.

The procedure has allowed us to classify the polygons composing the province according to their susceptibility to damage during DHEs. In high susceptibility polygons, severe damage occurs during rainfall characterised by low return periods; in medium susceptibility polygons maximum return period rainfall and induced damage show equal levels 
of exceptionality; in low susceptibility polygons, high return period rainfall induces a low level of damage. Concerning the type of phenomenon, flooding seems to be the least common type. $42 \%$ of the polygons are affected simultaneously by landslides and secondary floods, as well as $12 \%$ by landslides, floods and secondary floods.

The east and west sectors of the analysed province show the highest susceptibility, both after long and short intense rainfall. Polygons in the N-NE sector show the lowest susceptibility levels, on account of both their low population density and the high average rainfall values which characterise the climate of these mountainous areas.

The proposed methodology can also be applied to regions other than Calabria, as long as a rainfall dataset and historical data of damage concerning a severe DHE, are available. By using this methodology, the study area can be subdivided according to three levels of susceptibility to damage caused by DHEs.

The study of other DHEs that occurred in the same area can strengthen the procedure, providing a series of ranked damage/rainfall scenarios characterised by different levels of social and physical impact.

This type of research can supply useful information for the prediction of complete scenarios of damage according to rainfall characteristics. The knowledge of local event scenarios, in terms of rainfall amount, type of triggered phenomenon and induced damage, allow for the prioritizing of mitigation measures and can improve civil defence plans which take the possible simultaneous occurrence of all the types of phenomena which can arise during DHEs into account. In addition, these results can represent a base that can be broadened to a polygon scale, and which aim to assess local rainfall threshold for damage triggering.

Acknowledgements. The authors are grateful to A. Calendino for the rainfall-data elaboration. The useful suggestions of the Referee contributed to improve the work.

\section{Edited by: U. Ulbrich}

Reviewed by: M.-C. Llasat, P. Schmidt-Thom, and another anonymous referee

\section{References}

Aleotti, P.: A warning system for rainfall-induced shallow failures, Eng. Geol., 73(3-4), 247-265, 2004.

Amodio-Morelli, L., Bonari, G., Colonna, V., Dietrich, D., Giunta, G., Ippolito, F., Liguori, V., Piccarreta, G., Russo, M., Scandone, P., Zanettin-Lorenzoni, E., and Zuppetta, A.: L'arco CalabroPeloritano nell'orogene appenninico-maghrebide, Memorie Società Geologica Italiana, 17, 1-60, 1976.

Antronico, L., Sorriso-Valvo, M., Tansi, C., and Gullà, G.: Carta litologico-strutturale e dei movimenti in massa della Stretta di Catanzaro (Scala 1:50000). CNR-GNDCI, LINEA 2 - Previsione e Prevenzione di Eventi Franosi a Grande Rischio, Unità Operativa 2.56, GNDCI 2119, S.EL.CA., Firenze (Italy), 2001.

ArcView 3D Analyst Features, ESRI, 1998.

$\mathrm{Au}, \mathrm{S}$. W. C.: Rain induced slope instability in Hong Kong, Eng. Geol., 51, 1-36, 1998.

Benito, G., Lang, M., Barriendos, M., Llasat, M.C, Francés, F., Ouarda, T., Thorndycraft, V. R., Enzel, Y, Bardossy, A., Coeur, D., and Bobée, B.: Use of systematic, palaeoflood and historical data for the improvement of flood risk estimation, Review of Scientific Methods, Nat. Hazards, 31, 623-643, 2004.

Barnikel, F. and Becht, M.: A historical analysis of hazardous events in the Alps - the case of Hindelang (Bavaria, Germany), Nat. Hazards Earth Syst. Sci., 3, 625-635, 2003, http://www.nat-hazards-earth-syst-sci.net/3/625/2003/.

Caine, N.: The rainfall intensity-duration control of shallow landslides and debris flows, Geografiska Annaler, 62A(1-2), 23-27, 1980.

Caloiero, D. and Mercuri, T.: Le alluvioni in Calabria dal 1921 al 1970, CNR-IRPI Rende (Italy), Geodata, 7, 161 pp., 1980.

Caloiero, D., Gabriele, S., Govi, M., and Petrucci, O.: Il nubifragio del 13 marzo 1995 in Calabria meridionale ed in Sicilia orientale, GEAM, Geoingegneria Ambientale e Mineraria, Ass. Mineraria Subalpina, 19, 3-11, 1996.

Campbell, R.: Soil slips, debris flows and rainstorms in the Santa Monica Mountains and vicinity, Southern California, USGS Professional Paper, 851, p .51, 1975.

Cancelli, A. and Nova, R.: Landslides in soil debris cover triggered by rainstorm in Valtellina (Central Alps - Italy), Proc. IV Int. Conf. and field Workshop on Landslides, Tokyo, 1, 267-272, 1985.

Cannon, S. H. and Ellen, S. D.: Rainfall conditions for abundant debris avalanches, S. Francisco Bay region, California, California Geology, 38(12), 267-272, 1985.

Cascini, L. and Versace, P.: Eventi pluviometrici e movimenti franosi, Atti Convegno Nazionale di Geotecnica, Bologna, 3, 171 184, 1986.

Cardona, O. D.: The Need for Rethinking the Concepts of Vulnerability and Risk from a Holistic Perspective: A Necessary Review and Criticism for Effective Risk Management, in: Mapping vulnerability: disasters, development and people, edited by: Bankoff, G., Frerks, G.,and Hilhorst, D., Earthscan, London, 2004.

Catenacci, V.: Il dissesto idrogeologico e geoambientale in Italia dal dopoguerra al 1990, Cronistorie Calabresi. S.G.N., Mem. Carta Geologica d'Italia, Istituto Poligrafico e Zecca dello Stato, XLVII, 228-245, 1992.

Chowdhury, Md. R.: An Assessment of Flood Forecasting in Bangladesh: the Experience of the 1998 Flood, Nat. Hazards, 
22, 139-163, 2000.

D'Andrea, E. and Petrucci, O.: Gli eventi alluvionali calabresi del dicembre 2002-gennaio 2003, GNDCI, 2815, Editoriale Bios, Castrolibero (Italy), 161 pp., 2003.

Diodato, N.: Local models for rainstorm-induced hazard analysis on Mediterranean river-torrential geomorphological systems, Nat. Hazards Earth Syst. Sci., 4, 389-397, 2004, http://www.nat-hazards-earth-syst-sci.net/4/389/2004/.

Fan-Chien, Y., Chien-Yuan, C., Sheng-Chi, L., Shang-Yu, W., and Kei-Wai, C.: A web-based decision support system for slopeland hazard warning, Environ. Monit. Assess., 127, 419-428, 2007.

Giangrossi, L.: Nubifragi ed alluvioni in Calabria, Min. LL.PP. ed Associaz. Prov. Industriali Catanzaro, La Tipo Meccanica, Catanzaro (Italy), 85 pp., 1973.

Giannecchini, R.: Rainfall triggering soil slips in the southern Apuan Alps (Tuscany, Italy), Advances in Geosciences, 2, $21-$ 24, 2005.

Glaser, R.: Data and methods of climatological evaluation in historical climatology, Hist. Soc. Res., 21, 56-88, 1996.

Govi, M., Mortara, G., and Sorzana, P. F.: Eventi idrologici e frane, Geologia Applicata and Idrogeologia, XX, 2, 359-375, 1985.

Gullà, G., Antronico, L., Sorriso-Valvo, M., and Tansi, C.: Proposta metodologica per la valutazione di indicatori di pericolo e rischio da frana a scala intermedia: l'area della Stretta di Catanzaro (Calabria, Italia), Geologica Romana, 38, 97-121, 2005.

Guzzetti, F., Peruccacci, S., Rossi, M., and Stark, C. P.: Rainfall thresholds for the initiation of landslides in central and southern Europe, Meteorol. Atmos. Phys., 98, 239-267, 2007.

Hsu, M. H., Fu, J. C., and Liu, W. C.: Flood routing with real-time stage correction method for flash flood forecasting in the Tanshui River, Taiwan. J. Hydrol., 283, 267-280, 2003.

Ibsen, M. L. and Brunsden, D.: The nature, use and problems of historical archives for the temporal occurrence of landslides, with specific reference to the South coast of Britain, Ventnor, Isle of Wight, Geomorphology, 15, 241-258, 1996.

ISTAT (Istituto nazionale di statistica): $11^{\circ} \mathrm{Censimento} \mathrm{della} \mathrm{popo-}$ lazione, 1971.

ISTAT (Istituto nazionale di statistica): $14^{\circ} \mathrm{Censimento} \mathrm{della} \mathrm{popo-}$ lazione, 2001.

Jibson, R. W.: Debris flows in southern Puerto Rico, Geological Society of America, 236, 29-55, 1989.

Llasat, M. C., Barriendos, M., and Barrera, A.: The use of historical data in flood risk assessment. Application to Catalonia (NE Spain) 14th-20th centuries, In: View from the South, Environmental stories from the Mediterranean Word, CNR, edited by: Armiero, M., Istituto di Studi sulle Società del Mediterraneo, Napoli (Italy): 95-11, 2006.

Luino, F.: Sequence of instability processes triggered by heavy rainfall in the northern Italy, Geomorphology, 66(1-4), 13-39, 2005.

Mark, O., Weesakul, S., Apirumanekul, C., Aroonnet, S. B., and Djordjevic, S.: Potential and limitations of 1D modelling of urban flooding, J. Hydrol., 299, 284-299, 2004.

Ogniben, L.: Schema geologico della Calabria in base ai dati odierni, Geologica Romana, 12, 243-585, 1973.

Petrucci, O. and Polemio, M.: Hydro-geologic multiple hazard: a characterisation based on the use of meteorological and geomorphological data, in: Landslides, edited by: Rybar, J., Stemberk, J., and Wagner, P., Balkema Publishers, 269-274, 2002.
Petrucci, O. and Polemio, M.: The use of historical data for the characterisation of multiple damaging hydrogeological events, Nat. Hazards Earth Syst. Sci., 3, 17-30, 2003, http://www.nat-hazards-earth-syst-sci.net/3/17/2003/.

Petrucci, O. and Versace, P.: ASICal: a database of landslides and floods occurred in Calabria (Italy), in: Proc. 1st ItalianRussian Workshop: New Trends in Hydrology, Rende (Italy), 24-26 September 2002, edited by: Gaudio, R., CNR-GNDCI, 2823, 49-55, 2004.

Petrucci, O. and Versace, P.: Frane e alluvioni in provincia di Cosenza agli inizi del '900: ricerche storiche nella documentazione del Genio Civile, Editoriale Bios, Cosenza (Italy), ISBN: 88-7740-391-8, 172 pp., 2005.

Petrucci, O. and Versace, P.: Frane e alluvioni in provincia di Cosenza tra il 1930 e il 1950: ricerche storiche nella documentazione del Genio Civile, Nuova Bios, Cosenza (Italy), GNDCI, ISBN: 978-88-6093-029, 2913, 247 pp., 2007.

Petrucci, O., Chiodo, G., and Caloiero, D.: Eventi alluvionali in Calabria, Rubbettino Arti Grafiche, Soveria Mannelli (Italy), GNDCI 1374, 142 pp., 1996.

Petrucci, O., De Matteis, V., and Versace, P.: Aspetti metodologici nella identificazione dell'impatto al suolo degli eventi alluvionali, Convegno: La Difesa della Montagna Assisi (Italy), GNDCI, 2830, 522-530, 2003.

Plate, E. J.: Early warning and flood forecasting for large rivers with the lower Mekong as example, J. Hydro-environ. Res., 1, 80-94, 2007.

Polemio, M. and Petrucci, O.: Rainfall as a landslide triggering factor: an overview of recent international research, Proceedings 8th International Symposium on Landslides in Cardiff, June 2000: 1219-1226, 2000

Polemio, M. and Sdao, F.: Landslide hazard and critical rainfall in Southern Italy, Proceedings VII Int. Symp. on landslides, Norway, Balkema, Rotterdam, 847-852, 1996.

Remondo, J., Bonachea, J., and Cendrero, A.: Quantitative landslide risk assessment and mapping on the basis of recent occurrences, Geomorphology, 94, 496-507, 2008.

Rizzo, V. and Fragale, F.: Il rischio geologico nella programmazione territoriale, in: I sistemi informativi geografici per la pianificazione territoriale, edited by: Teti, M. A., Rubbettino, Catanzaro (Italy), 75-122, 1999.

Schmitt, T. G., Thomas, M., and Ettrich, N.: Analysis and modelling of flooding in urban drainage systems, J. Hydrol., 299, 300-311, 2004.

Sirangelo, B. and Braca, G.: Identification of hazard conditions for mudflow occurrence by hydrological model. Application of FLaIR model to Sarno warning system, Eng. Geol., 73, 267-276, 2004.

Sorriso-Valvo, M., Antronico, L., Gaudio, R., Gullà, G., Iovine, G., Merenda, G., Minervino, I., Nicoletti, P. G., Petrucci, O., and Terranova, O.: Carta dei dissesti causati in Calabria meridionale dall'evento meteorologico dell'8-10 settembre 2000, CNR-GNDCI, 2859, Geodata, 45, Rubbettino, Soveria Mannelli (Italy), 2004.

Tortorici, L.: Lineamenti geologico-strutturali dell'Arco CalabroPeloritano, Rendiconti della Società Italiana di Mineralogia e Petrologia, 38, 972-940, 1982.

Usul, N. and Turan, B.: Flood forecasting and analysis within the Ulus Basin, Turkey, using geographic information systems, Nat. 
Hazards, 39, 213-229, 2006.

Versace, P., Ferrari, E., Fiorentino, M., Gabriele, S., and Rossi, F.: Valutazione delle piene in Calabria, CNR-IRPI, Rende (Italy), Geodata, 30, 157 pp., 1989.
Zàruba, Q.: Vliv klimatických poměrů na smršťovàni kř̀dových slínů, Věda Př̀rodnì, 17, 1936. 